Ponto de vista

\title{
DIREITO, GÊNERO E FEMINISMO. UMA CONVERSA COM ELA WIECKO VOLKMER DE CASTILHO
}

\author{
Maurício Pereira Gomes \\ Universidade Federal de Santa Catarina, Florianópolis, \\ SC, Brasil \\ Morgani Guzzo \\ Universidade Federal de Santa Catarina, Florianópolis, \\ SC, Brasil
}

Ela Wiecko Volkmer de Castilho voltou a Florianópolis para participar de uma banca de defesa de tese (VENSON, 2015) no Programa de Pós-Graduação Interdisciplinar em Ciências Humanas da UFSC. O retorno à universidade na qual concluiu seu doutorado em Direito (1996) e lecionou durante 20 anos possibilitou o encontro com amigas e estudiosas da área de Gênero e a visita a seu filho, nora e neta no apartamento onde gentilmente nos recebeu para esta entrevista. ${ }^{1}$

Com mais de 30 anos de carreira no Ministério Público Federal, desde 1992, Ela Wiecko milita no cargo de Subprocuradora-Geral da República. Sua atuação jurídica e acadêmica tem como características o seu envolvimento com os direitos humanos e a sua estreita relação com os movimentos sociais. É professora associada da Universidade de Brasília (UnB), onde coordena projetos de extensão como a "Ação Continuada de Atendimento às Mulheres em Situação de Violência Doméstica e Familiar", na cidade-satélite de Ceilândia/DF.

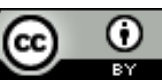

Esta obra está sob licença Creative Commons.

' Agradecemos à professora Joana Maria Pedro (UFSC) que facilitou o contato com a entrevistada. 
Seu nome já constou algumas vezes na lista tríplice da Associação de Procuradores da República do Ministério Público para o cargo de Procuradora-Geral da República. Na penúltima, em 2013, Ela Wiecko foi a segunda mais votada, depois de Rodrigo Janot, que acabou sendo nomeado pela Presidenta Dilma Rousseff.

Com a familiaridade e desenvoltura de quem transita e atua no centro político e jurídico do país há muitos anos, Ela Wiecko discorre sobre sua trajetória profissional, sobre gênero, lutas feministas e, claro, política.

894 Estudos Feministas, Florianópolis, 24(3): 893-903, setembro-dezembro/2016 
MORGANI GUZZO (MG): Como as questões de gênero e o feminismo surgiram em sua trajetória profissional no Direito e na Academia?

ELA WIECKO VOLKMER DE CASTILHO (EWVC): Lembro que, em 1986, na época da constituinte, quando eu era encarregada do setor de Direitos Humanos na Procuradoria da República aqui em Florianópolis, um grupo de mulheres da OAB Mulher que dava suporte ao chamado do "lobby do batom" - dentre as quais Sílvia Pimentel e Branca Moreira Alves - me procurou. A partir de então, eu passei a ter contato eventual com elas. Nos idos de 1992, 1993, por ocasião da Conferência Internacional dos Direitos Humanos em Viena, eu fui capturada por essas mulheres feministas. Havia muita discussão em torno das violações e dos estupros coletivos na Bósnia e eu assisti a algumas palestras de feministas. Na IV Conferência Mundial sobre a Mulher de Beijing, em 1995, mesmo eu não tendo sido escolhida para ir pela delegação brasileira, fui por minha conta. Assim, eu comecei a ter contato direto com algumas feministas, tornei-me amiga da Heleieth Saffioti e de outras que eram consultoras que trabalharam produzindo documentos para a posição brasileira.

Em todos esses anos eu não me nominava como feminista, mas já estava envolvida com a luta pelos direitos das mulheres. Então, em 1999, quando eu fui presidente da Associação Nacional dos Procuradores da República, eu promovi uma pesquisa para ver quantas mulheres estavam no Ministério Público Federal. Aos poucos, comecei a estudar as teorias feministas e me aproximei do NEPEN - Núcleo de Pesquisas sobre a Mulher, na UnB, quando eu fui convidada a ajudar a pensar um curso de capacitação para Policiais Militares, contribuindo com meu conhecimento na área do Direito. Isso lá pelo final dos anos 90, início dos anos 2000 . Elas me viam como uma parceira, pois éramos poucas mulheres: professoras da Antropologia, do Direito, da Sociologia, do Serviço Social, juntamente com seus orientandos e orientandas. Nos reuníamos todas as sextas-feiras para discutir os currículos dos cursos e foi aí que eu comecei a perceber como elas faziam isso na perspectiva feminista.

Eu digo que elas acabaram me capturando e investindo em mim, e, aos poucos, eu fui assumindo cada vez mais atividades relacionadas com as lutas feministas. Foi a partir da minha participação no consórcio de entidades feministas que estavam pensando um anteprojeto de Lei da Maria da Penha é que eu assumi mesmo.

MAURÍCIO PEREIRA GOMES (MPG): Essas entidades que você menciona participaram das discussões do projeto de lei que resultou na Lei Maria da Penha, no Congresso Nacional? 
EWVC: Sim, foi o seguinte: por volta de 2002, diferentes entidades feministas se reuniram e escreveram um anteprojeto de lei. No primeiro mandato do governo Lula, quando ele criou a Secretaria Especial de Políticas para as Mulheres, em 2003, nós oferecemos ao governo este projeto de lei. Então, a Ministra da pasta, Nilcéia Freire, formou um grupo interministerial e esse grupo se debruçou em cima da proposta do consórcio. Assim, acho que não chegou a um ano, esse projeto de lei foi encaminhado ao Congresso e lá houve uma série de alterações, inclusive com o aumento de penas, que não era contemplado em nossa proposta original.

Por tudo isso, a partir de 2006 é que eu senti a necessidade de passar para os alunos do Direito essa compreensão das teorias feministas. Então eu comecei a oferecer disciplinas sobre gênero e teorias feministas. Era um aprendizado conjunto, meu e de minhas alunas e alunos. Agora eu não tenho nenhuma dificuldade de dizer que eu sou feminista e assim me apresento.

MG: Qual sua avaliação quanto à importância e a efetividade da Lei Maria da Penha?

EWVC: Eu acho que a lei alterou muitas coisas e abriu caminhos. É uma lei que diz que o juiz tem que ouvir a equipe psicossocial. Assim, quando se cria um juizado especial, o poder judiciário tem que ter essa equipe de psicólogos, assistentes sociais, pedagogos. Isso é uma coisa positiva, porque, nesse tipo de conflito, você não tem como só dar uma resposta de interpretação jurídica, você tem de conhecer outros saberes que informem e que expliquem. Outra coisa importante é que a lei assegurou o direito de assistência jurídica à mulher. À polícia ela pode ir sozinha, mas, depois, ela sempre tem que ter um acompanhamento. Antes, as Defensorias Públicas só atendiam os agressores; agora, já foi percebida a necessidade de as Defensorias atenderem também as mulheres. Essa abordagem da equipe psicossocial e a assistência jurídica à mulher abriu caminho para se levar as questões para outros campos que têm intervenção jurídica. Também foi importante, pois colocou o tema na agenda: muitas pesquisas começaram a ser feitas, no âmbito das universidades, Ministério Público, além de projetos de extensão. Esse projeto de extensão que eu coordeno na UnB foi justamente para dar assistência jurídica à mulher.

Quanto aos aspectos negativos, a Lei tem esse viés da

${ }^{2}$ Referência à medida cautelar na Reclamação n 17.460, na qual restou definido que a suspensão condicional do processo não é aplicável nos casos de crime de violência contra a mulher.

\section{criminalização, mas eu não creio que ela trouxe impactos, por} exemplo, como a maior criminalização dos homens. Percebo que, muitas vezes, os processos criminais não andam ou, então, juízes e juízas, apesar da decisão do Supremo Tribunal Federal (STF), ${ }^{2}$ suspendem o andamento dos processos. Outras vezes, os juizados ou varas especializadas que já estão funcionando 
não implementam, na prática, a competência conjunta, com o que, em muitos casos, questões cíveis, criminais e de direito de família não têm uma solução conjunta e são resolvidas por juízes diferentes. A repercussão da lei ficou centrada muito na questão da criminalização e a solução não passa só por isso.

MPG: Você poderia falar do aprendizado que as equipes de trabalho têm tirado nas experiências de atendimento as mulheres em situação de violência doméstica e familiar no projeto de extensão que você coordena da UnB, realizado na cidade-satélite de Ceilândia?

EWVC: Nosso atendimento é interdisciplinar. Então, quando uma mulher chega, ela é atendida por alguém da área jurídica ou da psicologia, sendo certo que essas áreas estão sempre conversando para que as respostas jurídicas não sejam soluções prontas. Temos que prepará-las psicologicamente para as audiências; precisamos ver com elas as alternativas, soluções e encaminhamentos e ver, também, o que elas querem - a gente não impõe nada. Há um trabalho em conjunto com o Serviço Social que é muito importante..

MG: Durante a tramitação dos processos, quais são as dificuldades encontradas no tratamento jurídico dado às mulheres vítimas de violência?

EWVC: Mesmo nos Juizados Especiais de Violência Doméstica e Familiar contra a Mulher, onde se sabe que deve prevalecer o que mais atender aos interesses da mulher e à invocação aos princípios dos direitos humanos, eu já presenciei a prática muito forte de se fazer pouco caso das experiências vivenciadas pelas mulheres ou, então, de se fazer a leitura da situação a partir da experiência própria e não perceber que o contexto que está sendo julgado é diferente. Por exemplo, como os namoros acontecem em diferentes contextos e situações. Com o Ministério Público é um pouco diferente, porque há mais tempo funciona a Promotoria da Mulher, e ali foi feito um investimento de discussão sobre gênero e isso tudo. Algumas promotoras, inclusive, fizeram aquele curso de formação das promotoras legais populares, no qual elas interagiram com as mulheres do povo, então elas estão mais abertas para esse entendimento. Já os juízes, que são formados na escola de magistratura, lá eles têm alguma noção, mas é sempre aquela coisa, você vai, você fala, mas não é um trabalho de sensibilização. Então, muitas vezes, eles acabam reproduzindo os estereótipos. A Lei Maria da Penha é bastante indutora, ela é uma ação afirmativa, mas há muito a se fazer, criar metodologias que realmente consigam mexer com essas pessoas e romper com a arraigada naturalização da violência. 
MG: Seu nome constou algumas vezes na lista tríplice para assumir a Procuradoria Geral da República, inclusive com apoio da Associação dos Procuradores da República, mas não foi escolhido. Em outras oportunidades, você declarou que percebia uma dificuldade em se fazer ouvir nesse âmbito. Você pode falar um pouco das dificuldades motivadas pela questão de gênero que você enfrenta no campo profissional?

EWVC: Na escolha para a Procuradoria Geral da República, sempre prevaleceu o nome da pessoa mais votada. É uma prática que não é imposta pela lei, mas que é consensual, já que, em tese, qualquer pessoa que conste da lista tríplice pode ser escolhida. Então, quanto a isso, há outras considerações a serem feitas. Eu sempre, não na última vez, mas nas outras, eu era a única mulher. Então, identifico, aqui, uma dificuldade pois, para você vencer essa barreira e se tornar a mais votada, é muito difícil, porque, se você olha dentro do Ministério Público Federal, é constante a percentagem do número de mulheres na faixa dos $30 \%$, então, são os homens que, na realidade, votam e eles que definem o processo. É perceptível algumas situações, por exemplo: os homens podem chegar tarde em casa, no final de semana vão jogar futebol e, com as mulheres, é diferente. Quando elas têm filhos não podem ficar até mais tarde. E é nessas rodas, na roda do chopp, na roda do futebol, na roda do uísque, que os arranjos de poder são estabelecidos. Assim, as mulheres ficam alijadas desses momentos em que ocorrem as decisões. Por isso que as cotas são importantes. Uma coisa que eu queria dizer é que as cotas, por si só, não garantem todas as mudanças necessárias - e as mulheres podem ser machistas. Mas é muito importante ter cada vez mais mulheres nesses espaços de poder, políticos, representativos, no Congresso, nas instituições, nas empresas, em posições de poder, para que seja possível que, numa quantidade maior de mulheres, apareçam mais líderes e aquelas que se destaquem nos diversos campos.

MPG: Qual sua opinião com relação à Lei do Feminicídio que foi sancionada recentemente?

EWVC: De alguma forma, em virtude de minha atuação na Faculdade de Direito da UnB, eu também estive envolvida nas discussões que resultaram na Lei do Feminicício. Nossa posição, na faculdade, era centrada na importância de se nomear e dar visibilidade ao fenômeno das mortes por homicídio quando as vítimas são mulheres. A proposta da lei surgiu da Comissão Parlamentar Mista de Inquérito (CPMI) da Violência contra a Mulher, presidida pela deputada Jô Moraes (PCdoB/MG) e relatada pela Senadora Ana Rita (PT/ES), e contou com a assessoria da criminóloga feminista Carmem Hein de Campos. A proposta original desta comissão foi no sentido de inserir o feminicídio como circunstância qualificadora do crime de 
homicídio, mas o Congresso Nacional foi além e estabeleceu um aumento de pena.

O objetivo foi dar maior visibilidade ao problema. E isso traz consequências, como, por exemplo, um grupo de trabalho criado no âmbito do Conselho Nacional de Justiça e do Conselho Nacional do Ministério Público que está trabalhando na elaboração da versão brasileira de um documento, um tipo de protocolo, que vai estabelecer procedimentos a seguir nos casos de violência contra a mulher. Isso já existe no nível internacional: a Cúpula lbero-Americana tem um protocolo de como fazer a investigação quando a vítima é mulher. É um protocolo de investigação. Isso é muito importante no âmbito das políticas públicas. Eu participarei como observadora desse grupo de trabalho porque a ONU Mulheres, através da Vânia Pasinato, que também é uma feminista e que está prestando uma consultoria, está pensando em fazer um curso de formação em todos os Estados, que seja intersetorial, com participação da Polícia, Ministério Público, Defensoria Pública, Judiciário, e a Vânia pediu para o meu grupo de pesquisa conceber esse curso. Vai ser bem desafiador porque o objetivo é sensibilizar as pessoas. Elas têm que sair do curso transformadas, sabendo como trabalhar articuladamente e preocupadas em compreender por que aqueles atos de violência contra as mulheres aconteceram.

O que se está querendo, no caso da Lei do Feminicídio, é punir melhor, no sentido de dizer que os crimes praticados contra mulheres são praticados por misoginia, e isso interessa destacar para se dar uma resposta diferenciada, além de conferir visibilidade e demandar outras respostas do Estado. É estratégico. Não é uma ampliação da criminalização; é colocar as coisas em melhores termos. $O$ direito penal também ajuda.

MPG: A professora aplicaria o mesmo raciocínio no caso do projeto de lei de criminalização da homofobia?

EWVC: Sim, ela ficaria nesse mesmo patamar. Só destaco que eu sou contra essa tendência de aumentar as penas. Eu acho que tem de ficar dentro dos parâmetros que já existem e fazer toda uma reorganização.

Por exemplo, no caso do deputado Jair Bolsonaro (PP/RJ), eu apresentei denúncia contra ele no Supremo Tribunal Federal, por considerar que ele incitou à prática do crime de estupro ao criticar o pronunciamento da deputada federal Maria do Rosário (PT/RS) no Plenário da Câmara dos Deputados. Eu senti uma dificuldade de enquadrar o caso na hipótese de incitação ao crime. Teria sido mais fácil se uma lei estabelece de modo mais claro a proibição de praticar qualquer ato ou incitar a discriminação por motivo de sexo ou de gênero, a exemplo do que ocorre no caso do racismo. 
MPG: No Ministério Público Federal você lida com questões relacionadas com os direitos humanos e os povos indígenas. Sua visão de gênero impactou na sua atuação profissional nessas áreas? De que modo?

EWVC: Sim, por exemplo, com relação as mulheres indígenas eu até escrevi um artigo (2008) em que eu digo que elas é que têm que decidir se a elas se aplica ou não a Lei Maria da Penha, porque eu reconheço a autonomia dos povos indígenas. É claro que os e as indígenas que moram no meio urbano ou muito próximo dele não conseguem manter uma autonomia, somente possível quando preservada sua organização social, onde suas regras é que são impostas. Agora, na cidade, elas acabam procurando o delegado de polícia ou o juizado. $\mathrm{Na}$ realidade, eu reconheço que, na época dos debates em torno da Lei Maria da Penha, isso não foi discutido. A gente não podia pensar tudo e realmente não pensamos nas mulheres indígenas. Mas quando esse problema se colocou, porque depois da lei as mulheres começaram a procurar a FUNAl, aí eu entendi como a lei, dependendo do contexto, podia ser impositiva, uma lei que ia também contra elas. Por isso, pelo princípio da autodeterminação, considero que as indígenas têm que escolher se a lei é aplicável a elas ou não.

O feminismo é uma questão de direitos humanos, direitos de igualdade das mulheres. Então, não se pode separar. Os direitos humanos têm que estar permeados por todo um entendimento do que é o racismo, do que é o sexismo, todas essas discriminações que visam a diminuir o outro.

MG: Você faz parte do grupo que, há poucos dias, entregou ao presidente do STF o abaixo-assinado "Duas Gerações de Luta pelo Aborto Legal e Seguro", documento que pede a descriminalização do aborto. Na mesma semana, o deputado federal Jean Wyllys (PSOL/RJ) protocolou na Câmara dos Deputados um projeto de lei que versa sobre o mesmo tema.

EWVC: Sim, estou com uma cópia dele, é um projeto de lei que estabelece políticas de saúde reprodutiva, além de um artigo que descriminaliza o aborto, quando realizado com consentimento. Eu fiz uma breve leitura da proposta e achei muito interessante.

MPG: Por outro lado, o presidente da Câmara de Deputados, Eduardo Cunha (PMDB/RJ), recentemente desarquivou outras propostas que criminalizam o médico e quem dá assistência na realização do aborto. De modo geral, como você vê esse debate em torno do aborto no Brasil?

EWVC: Recentemente, eu estive em Montevidéu, onde ocorreu uma rodada de conversações sobre o tema. A posição oficial do Brasil no exterior é no sentido de descriminalização e regulação do aborto, mas isso não corresponde ao que é dito 
aqui dentro. Internamente foram feitas várias concessões em virtude dos partidos da base aliada, e, agora, vem uma "cruzada" do presidente da Câmara, desarquivando esses projetos de lei. Isso me faz lembrar do caso da Romênia, onde, durante a ditadura de Ceausescu (1966-1989), foi instituída uma política de Estado com o objetivo de aumentar a população. Então, o aborto, que era permitido, passou a ser proibido e as mulheres não tinham acesso a métodos anticoncepcionais, à camisinha, nada, e ficaram sem alternativas para prevenir a gravidez. Tem um filme, o "4 Meses 3 Semanas e 2 Dias", de 2007, que fala sobre essa questão horrível. E eu recentemente li um livro que conta o quanto isso fez mal para a Romênia, porque isso não impedia que os abortos acontecessem, aumentou a corrupção, as delações. Ficou um ambiente em que ninguém confiava em ninguém e uma geração de jovens em crise por acharem ou descobrirem que não tinham sido desejados.

Então esse fechamento, as tentativas de mudança da Constituição, de proibição do uso da pílula do dia seguinte e de qualquer iniciativa de educação sexual, meu Deus do céu! O que vai ser isso? A gente vai criar problemas que não existem, maiores ainda do que a gente tem hoje, porque o aborto, em alguns casos, tem certa permissividade. O que aconteceu no Rio de Janeiro, onde fecharam as clínicas e quem tomou conta dessa "demanda" foram as milícias, ali não tem lei, não tem ética. Então, eu vejo isso com certo pavor, porque não dá para fechar dessa forma. Nós levamos isso para a maioria dos ministros do STF. Levamos essas assinaturas, um pendrive com todos os documentos internacionais, das Conferências do Cairo, Beijing, dos Direitos Humanos, estatísticas dos custos com a mortalidade materna advindos das sequelas de abortos mal feitos, enfim, subsídios para os Ministros, caso alguma coisa chegue à Corte. Foi importante para dar visibilidade à questão, e alertar para o risco de retrocesso e de prejuízo ao estado laico. Eles mostraram preocupação.

MG: Quais as perspectivas, nesse embate, entre as propostas dos movimentos feministas organizados de liberação do aborto até doze semanas de gestação e essas iniciativas do presidente da Câmara?

EWVC: A percepção que tenho é a de que esse movimento, para retroceder, está tão forte, que já pode ser considerado um ganho se conseguirmos manter do jeito que está.

MG: Tendências como esta colocam em risco outras conquistas de direitos, como, por exemplo, o direito de adoção por casais homossexuais.

MPG: Mas há um limite, não é? Por exemplo, decisões do STF, como no caso da união estável e, por extensão, o casamento de 
casais homossexuais, eu acho que os ministros não admitiriam tamanho retrocesso pela via legislativa. O que você acha?

EWVC: Não haveria impedimento para que os projetos de lei fossem votados, mas, se convertidos em lei, caberia aos ministros declararem a inconstitucionalidade da iniciativa, por contrariar a Constituição Federal. Daí fica claro o quanto é importante a questão da escolha dos ministros do STF.

MG: Considerando as conquistas já alcançadas, quais os desafios que você percebe que estão colocados para os movimentos feministas a partir de agora?

EWVC: É inegável que o quadro, no Brasil, em termos de políticas públicas com perspectiva de gênero, avançou muito desde 2003. A criação da SPM foi importantíssima, assim como a Lei Maria da Penha, que é muito indutora, na medida em que criou necessidades nos estados, que tiveram que criar coordenadorias, secretarias, enfim, implementar políticas públicas nos níveis estadual e municipal.

Quanto aos desafios, eles são muito complexos. Alguns novos, outros antigos. A luta pelas cotas é um dos desafios. $O$ que se percebe é que há muitas mulheres jovens engajadas, se dizendo feministas, indo para a rua, participando. Uma geração que está discutindo as relações desiguais entre homens e mulheres e, também, homens que estão junto. Há uns dez anos eu não via isso com a clareza que vejo hoje. E essa luta pela igualdade não vai terminar. As coisas estão acontecendo, a tecnologia está em todos os espaços e as coisas mudam no âmbito do trabalho, no modo de fazer pesquisa, nas relações familiares, na forma como você é mãe, como você é pai. Muita coisa mudou e eu tento me manter antenada.

MG: Nesse sentido, você acha que as mobilizações sociais, muitas vezes organizadas pela internet, têm algum poder de influenciar nas decisões no âmbito do poder público e judiciário?

EWVC: Hoje, o poder de agregação que as redes sociais têm é impressionante. Sei que podem ter muita importância, como se deu, por exemplo, naquelas manifestações de junho de 2013 , quando o povo pegou a bandeira da Proposta de Emenda Constitucional $n^{\circ} 37$, com a qual pretendia restringir o poder de investigação criminal do Ministério Público. As manifestações foram muito importantes, porque nós íamos perder, e deu aquela virada. E foi aquela coisa de ir às ruas, mostrar os cartazes, então isso pressiona. O problema é que surgiram bandeiras totalmente sem fundamento. O que acontece é que as pessoas querem ser mobilizadas, elas querem ter uma bandeira e aí há o risco de elas serem mobilizadas pelas pessoas erradas, sob uma perspectiva distorcida. É perigoso isso. Agora, o Congresso sente a pressão, essa coisa das ruas, dos votos. 
MG: Você veio a Florianópolis para participar de uma banca de tese sobre o tráfego de pessoas, temática que também surge na sua atuação dentro do Ministério Público Federal. Qual a realidade brasileira nesse campo?

EWVC: Nos processos que a gente analisa, eu percebi que, em muitos casos, são de mulheres que querem ir para o exterior para exercer a prostituição e a nossa lei considera crime só o fato de dar qualquer auxílio que leve a uma pessoa, mulher ou não, para o exercício da prostituição. Então, de uma forma indireta, o que está sendo criminalizado é a prostituição. São pouquíssimos os casos em que se pode falar em atuação de uma máfia, pessoas que enganam e que exploram mulheres mandadas para o exterior.

Os 91 casos que são indicados pelo Brasil para o Escritório das Nações Unidas sobre Drogas e Crime (UNODC) revelam que, na maioria das situações, as mulheres sabiam que iam se prostituir, muitas já eram prostitutas aqui e queriam ir para lá para se prostituir. São realmente muitos poucos os casos em que elas não sabiam e chegaram lá e ficaram numa armadilha.

O problema é que polícia e o judiciário não escutam as mulheres. As redes de apoio são familiares e de amigos que ajudam. Um dos grandes problemas, para mim, é que o Brasil não enfrenta a prostituição, outro tema tabu que também não é regulamentado. O deputado Jean Wyllys (PSOL/RJ) também tem uma proposta para a regulamentação do trabalho sexual. Então as mulheres ficam na clandestinidade, esse trabalho é tratado como pecaminoso, imoral e não se discute isso. O que que eu estou falando é em termos do tráfico internacional. Outra coisa é deslocamento interno, que existe, é a exploração sexual que é direcionada às meninas e adolescentes e, para isso, tem que ter políticas públicas.

\section{Referências}

CASTILHO, Ela Wiecko Volkmer de. "A violência doméstica contra a mulher no âmbito dos povos indígenas. Qual lei aplicar?". In: VERDUM, Ricardo (Org.). Mulheres Indígenas, Direitos e Políticas Públicas. Brasília: INESC, 2008, p. 21-31.

VENSON, Anamaria Marcon. Tráfico Internacional de Pessoas para Exploração Sexual? Uma análise de processos crime (1995-2002). 2015. Tese (Doutorado Interdisciplinar em Ciências Humanas). Universidade Federal de Santa Catarina, Florianópolis. 